\title{
The relationship of short-term mindfulness and self-compassion meditation and the emotional well-being among middle aged female students in cyber university; pilot study
}

\author{
Lee Woo-kyeong ${ }^{1}$, Ju Se-jin ${ }^{2 *}$ \\ ${ }^{1}$ Department of Counseling Psychology, Seoul Cyber University \\ ${ }^{2}$ Department of Nursing, Namseoul University

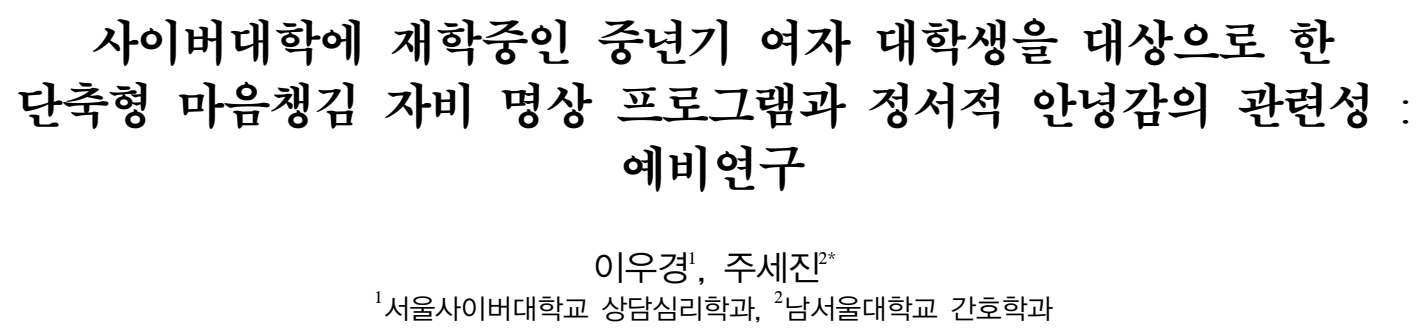

\begin{abstract}
A structured group program was implemented to facilitate mindfulness and self-compassion through a short meditation practices and its effects on the emotional well-being of counseling psychology students at a cyber university were observed. The participants attended a 4-week group program. Twenty-five total participants completed pre- and post-treatment measures of depression, psychological well-being, positive and negative emotions, mindfulness, and self-compassion. This program could provide a useful experiential introduction to mindfulness and self-compassion training for counseling undergraduate psychology students. Future studies should address the effects of practice on the mindfulness and self-compassion in larger student groups exposed to a range of stressful situations.

요 약 본 연구에서는 서울시내에 있는 $\mathrm{S}$ 사이버대학교 상담심리학과에 재학중인 대학생을 대상으로 단축형 집단 프로그램 을 실시하고 그 효과를 살펴보았다. 본 연구에서 사용된 명상 프로그램은 마음챙김 인지치료와 자기-자비 프로그램을 혼합한 프로그램으로 구조화된 집단 프로그램 형식으로 구성되었으며 참가자들의 정서적 안녕감을 증진시키는 것을 목표로 하였다. 단축형 집단 프로그램에 참여한 참가자들은 4 주간의 오프라인 집단 프로그램에 참여하였다. 전체 25명의 참가자들은 프로그 램 사전과 사후에 우울, 심리적 안녕감, 긍정 및 부정적 정서, 마음챙김 및 자기 자비 측정치들을 실시하였다. 본 연구는 마음 챙김 및 자기 자비 명상이 상담심리 대학생들의 심리적 안녕감에 미치는 긍정적인 영향을 살펴볼 수 있는 경험적 기초를 제공해주고 있다. 향후 심리학 전공 대학생 외에 여타의 다른 전공 대학생들을 대상으로 마음챙김과 자기 자비 명상을 접목 한 프로그램을 실시하여 다양한 스트레스 상황에 노출되어 있는 대학생들의 정신 건강에 이 프로그램이 어떤 영향을 미치는 지 반복 검증해보는 것이 필요할 것이다.
\end{abstract}

Key Words : Emotional Well-being, Mindfulness, Self-compassion meditation

\section{Introduction}

University life poses many challenges to students' psychological well-being, asking that they both meet academic goals and manage their emotional reactions to academic stress [1].

${ }^{*}$ Corresponding Author : Ju Se-jin(Namseoul Univ.)

Tel: +82-41-580-2714 email: lovepdd@nsu.ac.kr

Received February 25, 2014 Revised (1st March 31, 2014, 2nd April 15, 2014, 3rd April 29, 2014, 4th May 8, 2014)

Accepted June 12, 2014 
A new type of higher education system called cyber universities was established in the last decade in South Korea. They began in 2001 with 9 universities and 6,220 students and, are developing at an incredible rate [2]. Now, total 21 cyber universities in South Korea provide a new learning environment for people who have not had higher educational opportunities, allowing them to receive online lectures or smart learning, without time or space limits. Meanwhile, the popularity of psychology as an academic and social field has exploded since 2000 in South Korea. About 25\% of S Cyber University's students are enrolled in a counseling psychology undergraduate program [3]. Almost two-thirds of the undergraduate students majoring in counseling psychology at this cyber university are adult women (aged 40-55 years). According to a national survey performed in 2001, the lifetime prevalence of depression in South Korea is 4\%, and Korean middle aged women report three times the rate of lifetime depression diagnosis of Korean adult men. Many Korean adult women suffer from depression, anxiety, and a culture-bound syndrome, called Hwa-Byung [4]. Hwa-Byung translated into English as "anger disorder".is a disease, used by Koreans to explain a myriad of physiological and psychological problems.

Hwa-Byung is believed to develop through interaction between culturally imposed emotional repression, conflict avoidances, and experience with chronic adversities[4].

Korean mental health professionals have suggested that role-specific stress in these middle aged women can lead to Hwa-Byung, increased psychological distress, depressive mood, decreased life satisfaction, and even suicide. Many Korean middle aged women need social support to deal with various role-specific stressors (e.g., those associated with being mothers, wives, caregivers, and students etc) in their lives $[4,5]$.

Considering these difficulties, psychological interventions for these middle aged women students are necessary in order to enhance both their personal well-being and their academic and professional pursuits. Almost all programs developed in South Korea to improve emotional well-being and mental health are directed toward a specific illness with a limited range of symptoms [5]. Recent research has reported that substantial evidence that mindfulnessbased interventions decrease psychological problems, and enhance nonclinical individuals' mental health [6]. Mindfulness-Based Stress Reduction (MBSR) focuses on enhancing mindfulness skill through bare attention to present moments and experiences[7,8]. Meanwhile, Mindfulness-Based Cognitive Therapy (MBCT) is a mindfulness meditation based intervention that targets emotional distress in a wide range of clinical populations[9]. MBCT encourages patients who have mental disorder to "disidentify" with or "decenter" themselves from negative self-judgment or ruminative thinking patterns [9]. Thus, MBCT targets cognitive reactivity as a component of the cognition-affect cycle [9, 10, 11]. MBCT's beneficial applications have not been limited to the clinical populations, its benefits, such as decrease in perceived stress and psychological distress among medical and pre-medical students [6], mental health professionals [12] and counseling students [13] have been consistently reported. Further, this intervention also impact professional pursuit by enhancing participants' ability for empathy and improving their listening skills [13].

Self-compassion is another construct from Buddhist psychology that has received research attention [14,15]. Mindfulness and self-compassion are interrelated; while mindfulness refers to nonjudgmental attention to one's experience, self-compassion brings mindful awareness of negative self-judgment and kind feelings toward oneself as well as insight into the universality of human experiences [14,15]. Several therapies now focus on the importance of helping people develop inner compassion and self-soothing skill. Other researchers have also suggested the possible advantages of a combination of mindfulness and self-compassion training to address depressive 
mood and other psychological problems[16].

For example, self-compassion is negatively correlated with self-criticism, rumination, anxiety, depression, rumination, thought suppression, and neurotic perfectionism, but positively associated with social connectedness and life satisfaction [14]. High levels of self-compassion predict increased psychological health over time, and explain decreased stress following participation in stress-reduction training [12.17].

Another strength of self-compassion is the ability to deal with life stressors such as academic failures [18], divorce [19], or childhood maltreatment [20]. The individuals who have high level of self-compassion show improved relationship functioning, and report more altruism, perspective taking, empathetic attitude, and forgiveness than others[21-23]

Considering this background, the current study was designed to investigate the combined effects of $\mathrm{MBCT}$ and self-compassion training on the psychological well-being of undergraduate students majoring in counseling psychology at a cyber university. There are other reasons-both theoretical and practical- for using $\mathrm{MBCT}$ as a primary intervention to enhance the emotional well-being of Korean adult cyber university students. First, the basic attitudes of mindfulness, (e.g., "letting go", "acceptance", and "non-striving"), are congruent with the life philosophies of Eastern societies such as that of South Korea [5]. Especially, the "letting go", or "non-attachment" attitude of life suffering has been inherent in Korean tradition and culture. Second, mindfulness-based interventions encourage one to view one's thoughts as they are rather than struggling or attempting to change their contents. Therefore, MBCT was adopted as a main program since it may be more beneficial to Korean adult undergraduates who are familiar with a traditional life philosophy. Third, in addition to providing students with an opportunity to learn potentially useful therapeutic skills which are both specific and general in nature, MBCT might be effective for coping with role-specific stress or depressive mood. We believe that there are other reasons for combining $\mathrm{MBCT}$ with self-compassion training. Just as in mindfulness-based program, self-compassion training also emphasizes turning one's attention inward, thereby enhancing a perspective of inter-connectedness and self-acceptance [14, 15]. Many adult counseling psychology undergraduate students in cyber universities suffer from stress overload due to their multiple daily roles, in addition to being adult learners, they are parents to their children, spouses, and caretakers to their older parents. In consideration of these facts, we believe that self-compassion training may help to reduce adult students' overall life stress by decreasing their academic stress, further the sense of guilt, and the self-critical attitude that are contingent on their other stressors, consequently encouraging their self-kind or self-soothing skills. There are lack of empirical researches on the relationship between the duration and frequency of meditation practice and therapeutic outcomes. Thus, the purpose of the present study was to implement a pilot program comprised of mindfulness exercise typical of those used in MBCT and self-compassion training, but with considerably shorter practice length and program duration. We hypothesized that shorter MBCT sessions and self-compassion enhancement training in a group format would decrease psychological problems and negative emotion in counseling students. Furthermore, we also hypothesized that $\mathrm{MBCT}$ combined with self-compassion training would benefit students through increased psychological well-being, mindfulness skills, and self-compassion

\section{Method}

\subsection{Participants}

We conducted the participant recruitment process through online banner advertisements, e-mails solicitations, and online classroom presentations, during fall semester of 2011. These advertisements introduced 
the program as the "psychological well-being enhancement program: Mindfulness combined self-compassion training". The inclusion criterion for the study was that the participants needed to have time to attend at least three live practice sessions. Initially, 35 students showed interest in the program; however, only 29 students consented to participate in the live group sessions and evaluation. None of the participants had pre-course meditation experience. Four participants were not included in the final evaluation: two attended fewer than three sessions, one did not complete the post-course questionnaire, and one did not complete the pre-course questionnaire. Thus, 25 middle aged undergraduates attended the live group sessions and completed the study. The participants' descriptive statistics are presented in Table 1. All participants were female students and the average number of sessions attended was 3.48 sessions. There were no significant differences between completers and those who attended fewer than all four sessions in terms of age. The pre-BDI histogram indicates that 5(20\%), 14(56\%), 3(12\%), and 3(12\%) students were non-depressed and, had mild, moderate, and severe depression, respectively. Eighty percent of the participants had mild to severe depression at the time of intervention.

\subsection{Design}

This research was conducted in the fall semester of the 2011 academic year. A repeated measures design was used. The design enabled within-subjects comparisons of pre-and post-course self-report measures.

[Table 1] Demographic Variables

\begin{tabular}{lll}
\hline Variables & & Frequency(\%) \\
\hline Age(years) & & $41.61(5.31)$ \\
Occupation & Professional & $2(8 \%)$ \\
& Clerical & $8(32 \%)$ \\
& Work & $7(28 \%)$ \\
& Full time wife & $8(32 \%)$ \\
Religion & Christian & $9(36 \%)$ \\
& Catholic & $5(20 \%)$ \\
& Buddhism & $3(12 \%)$ \\
& No religion & $8(32 \%)$ \\
\hline
\end{tabular}

\subsection{Procedure}

After obtaining approval from the applicable university ethic boards, we recruited participants through online classroom presentations. In addition, information about the program was emailed to all undergraduate students majoring in counseling psychology. Respondents received brief interviews and gave their written informed consent to participate. Participants who consented to the evaluation were asked to complete self-report measures before starting the program and at the final session. These data were collected anonymously to make sure participant confidentiality. The program employed a 4 week (3h per week) format. At first, we tried 6 and 8 session program. However, the drop rate was high in 6 or 8 session program respectively. It was very difficult for adult female students to participate for 6 or 8 consecutive session because they were very busy working and studying. The duration of meditation was minimum 30 min during each session. The mindfulness and self-compassion exercises were constructed specifically for these brief sessions. The main theme of each session was described in [Table 2].

\subsection{Interventions}

The program drew mainly on the Korean version [24] of the MBCT manual, the original version of which was developed by Segal et al. [9]. Participants received training in the following meditative practices; (1) raisin meditation for moment-to moment awareness; (2) sitting meditation, involving awareness of bodily sensations, thoughts, and emotions with focus on breathing; (3) body scan, a progressive movement of attention throughout the body from the toes to the head, with non-judgmental observation of sensations within different areas of the body; and (4) a 3-min breathing space, which foci on breathing, the body, and in the present moment.

All of these techniques emphasize mindfulness and continuously maintain participants' attention on the present moment. Session 1(Automatic pilot), Session 
[Table 2] MBCT sessions combined with self-compassion

\begin{tabular}{|c|c|c|}
\hline $\begin{array}{l}\text { Sessions } \\
\text { Themes }\end{array}$ & Agenda & Home practice \\
\hline Session 1 & Establish the orientation of the program & $\begin{array}{l}\text { Eating } \\
\text { meditation }\end{array}$ \\
\hline \multirow[t]{3}{*}{$\begin{array}{l}\text { Automatic } \\
\text { pilot }\end{array}$} & Distribute Session 1 handouts(including homework record forms) & $\begin{array}{l}3 \text {-Minutes on the breath } \\
\text { every day }\end{array}$ \\
\hline & Raisin exercise and feedback & $\begin{array}{l}\text { Self-compassion } \\
\text { exercise }\end{array}$ \\
\hline & $\begin{array}{l}\text { Self-compassion exercise } \\
\text { End the class with a short breath focus, } 3 \text { minutes on the breath }\end{array}$ & \\
\hline Session 2 & Practice \& homework review & Body Scan \\
\hline \multirow[t]{2}{*}{ Mindfulness of Body } & Distribute Session 2 handouts(focusing on the awareness of body) & $\begin{array}{l}\text { 3-Minute on the breath } \\
\text { everyday }\end{array}$ \\
\hline & $\begin{array}{l}\text { Body Scan practice-starting with a short breath focus } \\
\text { Walking meditation and Feedback } \\
\text { Self-compassion exercise }\end{array}$ & Self-compassion exercise \\
\hline Session 3 & Practice \& homework review & 3- Minute Sitting meditation \\
\hline \multirow[t]{4}{*}{$\begin{array}{l}\text { Mindfulness of } \\
\text { Emotions }\end{array}$} & $\begin{array}{l}\text { Distribute Session } 3 \text { handouts(focusing on the acceptance of emotional } \\
\text { experiences) }\end{array}$ & Self-compassion exercise \\
\hline & 20-Minute sitting meditation-awareness of emotion & \\
\hline & Read Rumi's poem & \\
\hline & Self-compassion exercise & \\
\hline Session 4 & Practice \& homework review & $\begin{array}{l}\text { Daily mindfulness exercise } \\
\text { Daily self-compassion } \\
\text { exercise }\end{array}$ \\
\hline \multirow{6}{*}{$\begin{array}{l}\text { Mindfulness of } \\
\text { Thought }\end{array}$} & $\begin{array}{l}\text { Distribute Session } 4 \text { handouts(focusing on the thought } \\
\text { relationships) }\end{array}$ & \\
\hline & 20-Minute sitting meditation-awareness of thought & \\
\hline & $\begin{array}{l}\text { Moods, thoughts, and alternative viewpoints exercise, } \\
\text { Self-compassion exercise }\end{array}$ & \\
\hline & $\begin{array}{l}\text { Check and discuss plans, and link them to positive reasons for } \\
\text { maintaining the practice }\end{array}$ & \\
\hline & Summary of all sessions & \\
\hline & End the class with a concluding meditation & \\
\hline
\end{tabular}

3(Mindfulness of breath), Session 4(Staying present), Session 5(Allowing/Letting be), and Session 6(Thoughts are not facts) from MBCT were included, whereas MBCT Session 2, 7, and 8 from were left out. MBCT originally targeted depression, but this intervention targeted enhancement of psychological well-being, as well as decreasing of depressive feelings because eighty percent of the participants showed mild to severe depression.

In addition to the mindfulness exercises, "self-compassion" meditation was included in order to help participants develop greater compassion for themselves. Self-compassion exercises were based on the scripts devised by Neff(www.self-compassion.org).

Each participant received the handouts which included the session agenda and homework. The handouts were based on the Korean version of MBCT and self-compassion exercises. The audio file of meditation scripts were also distributed to the participants for homework practice. All sessions were conducted in Korean. The MBCT was translated and published by the present author, who also translated the self-compassion exercises [24].

All participants gathered in the counseling center, an affiliated organization of the university, once a week. Each session started with a discussion of any problems or issues from the previous week related to the homework, continued with exercises, and ended with a session evaluation. The intervention consisted of four 3-h live sessions. For first $40 \mathrm{~min}$, we discussed of any problems from the previous week's homework: then for the next $50 \mathrm{~min}$, we introduced the main topics or themes of the session to the participants. Subsequently, after a 10 min break, the participants completed 30 min 
of meditation practice and then feedback and discussion of meditation followed for the next $30 \mathrm{~min}$. The participants then received their homework assignment for the next 17 min. Finally, we ended the session with a 3-min breathing space. Participants were asked to practice their mindfulness meditation training outside the group environment for at least for 30 minutes each day (including a 3-minute breathing space, three times daily)

The intervention was led by a clinical psychologist with 7 years' experience in MBCT and 10 years' of experience in Cognitive Behavior Therapy (CBT).

\subsection{Measures}

\subsubsection{Mindfulness Scale}

The mindfulness scale we used was developed by the Korean psychologist [25]. This scale consists of 20 items that assess individuals' mindfulness skills. Park identified four factors: decentered attitude, non-judgmental acceptance, present awareness, and attention. The overall internal consistency reliability (Cronbach a) of the scale was .88. The convergent validity with a well-validated mindfulness scale, the Mindful Attention Awareness Scale (MAAS, Brown \& Ryan, 2003), was good (correlation coefficient $=.70$ ) [39].

\subsubsection{Self-Compassion Scale}

The Self-Compassion Scale is a 26-item questionnaire designed to measure three components of self-compassion: self-kindness, common humanity, and mindful acceptance of painful thoughts and feelings rather than overidentifying with them and Neff (2003a)reported a Cronbach's a coefficient of .92 for this scale [14]. In the present study, we used a version of the scale that had been translated into Korean [26]. The Korean version of the SCS was translated by five clinical psychologists including myself and backtranslated by a Korean-American scholar who is familiar with both Korean and English. The factor structures remain the same in this Korean version. The
Korean version of the SCS showed good internal consistency (Cronbach's a coefficient of .87 for this version).

\subsubsection{Positive and Negative Affect.}

This study used the widely used Positive and Negative Affect Schedule(PANAS) [27]. This scale is comprised of two subscales: a 10-item negative and positive affect subscales which assess the degree to which participants experience moods such as "upset" / "nervous" or "excited" / "proud," respectively. We used the Korean version translated by Cho(2007) who reported Cronbach's a coefficient of .88 and .84 for the positive and negative affect subscales, respectively [28].

\subsubsection{Beck Depression Inventory}

The Beck Depression Inventory (BDI) is a self-report scale that was developed to assess severity of depression [29]. Tenty-one items are rated on a 4-point scale with the total score obtained via summation. Lee \& Song(1991) assessed the validity and reliability of the Korean version of the scale [30]. The Cronbach's a coefficient of the Korean version of the BDI was .92.

\subsubsection{Psychological Well-Being}

The Psychological Well-Being (PWB) scale is a self-report inventory that measures six dimensions of psychological well-being, including environmental mastery, self-acceptance, life purpose, and personal growth [31]. We used the reduced 18-item version of the scale, which has been translated into Korean [32]. The Cronbach's a coefficient of the Korean version of the PWB was .89.

\subsection{Data Analysis}

After the 4-week program, change analyses were performed using non-parametric Wilcoxon's tests because of the small sample size employed. Bonferroni correction $(\mathrm{p}=.05 / \mathrm{n})$ was applied to control for Type I 
error due to multiple comparisons. Pearson's correlations were used to investigate the associations between changes in the questionnaire measures. An alpha level of .05 was used as the threshold for statistical significance in all analyses. SPSS Version 20.0 for Windows was used for statistical analysis.

\section{Results}

\subsection{Changes in Emotional Well-Being}

Table 3 shows the pre- ${ }^{-}$and post-intervention means and SDs in terms of on affect and depression. Wilcoxon signed rank tests were used to compare the pre-course and post-course outcome measures. As hypothesized, there were significant improvements in overall scores on the PWB $(z=3.750, \quad \mathrm{p}<.001), \quad$ PANAS-P $(z=3.138, \mathrm{p}<.01), \quad$ PANAS $-\mathrm{N}(z=-2.560, \quad \mathrm{p}<.01)$,BDI $(z=-3.544, \mathrm{p}<.001)$.

\subsection{Changes in Mindfulness and Self- Compassion}

Mindfulness significantly improved overtime $(z=2.452, p<.01)$. Further, self-compassion, asassessed by the SCS, also significantly improved overtime $(z=4.119, \mathrm{p}<.001)$. [Table 3].

\subsection{Correlation Analyses}

Table 4 shows the correlations between participants' changes in mindfulness skill on the one hand and positive and negative affect on the other over the course of the intervention. The results of correlational analysis between the Mindfulness Scale and related variables showed that increased mindfulness was associated with decreased negative affect $(r=-.542$, $\mathrm{p}<.01$ ). Furthermore, increased self-compassion was significantly related to increased positive affect $(r=.622$, $\mathrm{p}<.01)$.

\section{Discussion}

The purpose of this study was to determine whether MBCT administered in conjunction

with self-compassion training effectively reduces psychological symptoms and enhance emotional well-being in Korean counseling psychology students, who often suffer from considerable psychological distress. This study was conducted as a preliminary investigation into the use of brief mindfulness sessions and provided an experiential introduction to mindfulness and self-compassion training for undergraduate counseling psychology students who had mild to severe depression.

[Table 3] Means (and SDs) of psychological measures at pre- and post-intervention

\begin{tabular}{lllcl}
\hline & Pre & Post & Z value & $\mathrm{p}$ value \\
\hline PWB & $71.54(10.15)$ & $87.77(11.36)$ & +3.750 & $.001 * * *$ \\
PANAS-P & $25.90(6.82)$ & $29.36(5.87)$ & +3.138 & $.01 * *$ \\
PANAS-N & $22.50(8.74)$ & $18.00(7.70)$ & -2.560 & $.01 * *$ \\
BDI & $12.68(6.82)$ & $5.72(6.90)$ & -3.544 & $.001 * * *$ \\
MS & $46.54(16.78)$ & $58.86(10.88)$ & +2.452 & $.01 *$ \\
SCS & $77.18(18.17)$ & $86.72(16.94)$ & +4.119 & $.001 * * *$ \\
\hline
\end{tabular}

[Table 4] Correlations between changes in related variables

\begin{tabular}{|c|c|c|c|c|c|c|}
\hline & $\triangle \mathrm{MAAS}$ & $\triangle \mathrm{SCS}$ & $\triangle \mathrm{BDI}$ & $\triangle \mathrm{PWB}$ & $\triangle$ PANAS-P & $\begin{array}{c}\triangle \text { PANAS } \\
-\mathrm{N}\end{array}$ \\
\hline$\triangle \mathrm{MS}$ & 1 & & & & & \\
\hline$\triangle \mathrm{SCS}$ & -.138 & 1 & & & & \\
\hline$\triangle \mathrm{BDI}$ & -.056 & .332 & 1 & & & \\
\hline$\triangle \mathrm{PWB}$ & -.020 & -.248 & -.163 & 1 & & \\
\hline$\triangle$ PANAS-P & .079 & $.622 * *$ & .085 & .255 & 1 & \\
\hline$\triangle$ PANAS-N & $-.542 * *$ & -.027 & .181 & .025 & .130 & 1 \\
\hline
\end{tabular}


MBCT was originally designed to prevent relapse into depression among individual who suffer from chronic depression. Eighty percent of this study's participants reported mild to severe depression at the time of the intervention. The results revealed that post-treatment psychological symptom scores were significantly lower than baseline. These results are consistent with those of a previous study [33], which suggested that mindfulness-based interventions could reduce psychological symptoms. Studies from different patient groups have shown that meditation-based therapy results in immediate post-treatment improvements in anxiety and depressive symptoms[6]. Recent meta-analytic reviews have suggested that MBCT lead to significant improvements in psychological functioning in a wide range of study populations [34,35]. Self-compassion and mindfulness scores also improved significantly after intervention. There is growing evidence that participation in MBSR and MBCT increases self-compassion [5,12,36,37,38].

Although our program was somewhat different from MBSR, the present results showed that MBCT combined with self-compassion training also increased participants' mindfulness and self-compassion levels. Considering that increased mindfulness was associated with decreased negative affect and that increased self-compassion was significantly related to increased positive affect, we suspect that MBCT combined with self-compassion training might be a useful intervention for relief of negative affect, and enhancement of positive affect via mindfulness and self-compassion.

A significant limitation of this study was its generalizability. As the participants were all volunteer female undergraduates, the results may not be fully applicable to other populations such as male students. In addition, we cannot conclude that the observed changes were actually attributable to the MBCT plus self-compassion training because of the lack of a control group, The "first come, first served" recruitment method (i.e., convenience sampling) may have also led to sampling bias, such as the inclusion of a disproportionately high number of undergraduate students who were enthusiastic about taking part in the study.

Another limitation was that this study depended entirely on self-report measures, leaving it difficult to unknown whether the positive results reflect true trend or demand characteristics. Further, this study did not include any other physiological or behavioral measures of well-being. Future research could include multidimensional outcome measures, which evaluate physiological or behavioral changes. Furthermore, the present study did not include any long-term follow-up data, thus, we cannot be sure that the beneficial effects of the program will persist in the long-term.

Despite these limitations, this study has several strengths. The current findings are consistent with those of previous research (Hofmann et al., 2010; Lee \& Bang, 2010) in that mindfulness and self-compassion can be cultivated and is beneficial to emotional well-being. This study also provides support for the integration of self-compassion training into $\mathrm{MBCT}$ in nonclinical populations. In South Korea, mindfulness and self-compassion-based psychological interventions are still in their early stage. Most stress management and emotional well-being programs in Korea are based on cognitive behavioral psychology. However, the intervention used in present study was devised to promote internal growth and self-understanding, and enhance emotional well-being of adult undergraduate cyber university students who suffer from various forms of psychological distress. The results of the current study support the notion that mindfulness and self-compassion could help to maintain students' psychological well-being and positive mental health. Given the difficulties of cyber university middle aged women students who often have jobs in addition to their studies, we believe that attempts to help them develop greater mindfulness and self-compassion would be beneficial to their overall emotional well-being. In particular, self-compassion may help these middle aged women undergraduates to 
experience positive feelings towards themselves without being self-critical and self-judgmental. Self-compassion could also alleviate individuals' daily life suffering including academic stress, and help them to see their life problems as universal matters with which all human beings must confront [14,15].

\section{Conclusion}

Compared with the usual eight sessions, the shorter sessions and $30 \mathrm{~min}$ brief mindfulness practices were still adequate to facilitate participation and allow for statistical analysis of the self-report measures. Thus, though the program was short, it still impacted on measures of mindfulness, self-compassion, and psychological well-being. Further research is required to clarify the impact of duration and frequency of practice on mindfulness and self-compassion skills. These studies would be beneficial for consideration of the potential efficacy of brief mindfulness training sessions on the emotional well-being for middle aged women students majoring in counseling psychology.

\section{References}

[1] Schneiderman, N, Ironson, G., \& Siegel, S. "Stress and health: Psychological, behavioral, and biological determinants". Annual Review of Clinical Psychology, 1, $607-628,2005$.

DOI: http://dx.doi.org/10.1146/annurev.clinpsy.1.102803.144141

[2] Korean Ministry of Education, Science, and Technology. Higher education statistics, 2012.

[3] Seoul Cyber University. Annual statistics, 2012.

[4] Ji, S.E., Kim, J.W, Hwang, E.W, \& Cho, H.S. "The study on the clinical aspects of Hwabyung Patients". Journal of Oriental Neuropsychiatry, 8(2), 63-84, 1997.

[5] Lee, W. K, \& Bang, H. J. "Effects of mindfulness-based group intervention on the mental health of middle-aged Korean women in community“.Stress and Health, 26,341 348, 2010.

[6] Shapiro, S.L., Schwartz, G.E., \& Bonner, G. "Effects of mindfulness-based stress reduction on medical and premedical students". Journal of Behavioral Medicine, 21
(6), 581-599, 1998

DOI: http://dx.doi.org/10.1023/A:1018700829825

[7] Kabat-Zinn, J. "Mindfulness-based interventions in context: Past, present, and future. Clinical Psychology" : Science \& Practice, 10(2), 144-156, 2003.

DOI: http://dx.doi.org/10.1093/clipsy.bpg016

[8] Kabat-Zinn J. "Coming to our sense". New York : Hyperion, 2005.

[9] Segal, Z.V., Williams, J.G., \& Teasdale, J.D. Mindfulness-based cognitive Therapy for depression NewYork, London :The Guilford Press, 2002.

[10] Teasdale, J.D. "Metacognition, mindfulness and the modification of mood disorders". Clinical Psychology and Psychotherapy, 6,146-155, 1999a DOI: http://dx.doi.org/10.1002/(SICI)1099-0879(199905)

[11] Teasdale, J.D. "Emotional processing, three modes of mind and the prevention of relapse in depression". Behavior Research Therapy, 37, 53-77, 1999b. DOI: http://dx.doi.org/10.1016/S0005-7967(99)00050-9

[12] Shapiro, S.L, Astin, J.A. Bishop, S.R, \& Cordova, M. "Mindfulness-based stress reduction for health care professionals: results from a randomized trial". International Journal of Stress Management,12(2), 164-176, 2005.

DOI: http://dx.doi.org/10.1037/1072-5245.12.2.164

[13] Schure, M. B., Christopher, J., \& Christopher, S. "Mind-body medicine and the art of self-care: Teaching mindfulness to counseling students through yoga, meditation, and qigong". Journal of Counseling and Development, 86, 47 - -56, 2008.

DOI: http://dx.doi.org/10.1002/j.1556-6678.2008.tb00625.x

[14] Neff, K.D. "The development and validation of a scale to measure self-compassion". Self and Identity, 2, 223-250, 2003a.

DOI:10.1080/15298860309027

[15] Neff, K.D. "Self-compassion: An alternative conceptualization of a healthy attitude toward oneself". Self and Identity, 2, 85-102, 2003b. DOI:10.1080/15298860309032

[16] Allen, N.B., Knight, \& W.E.J. Mindfulness, compassion for self, and compassion for others. Implications for understanding the psychopathology and treatment of depression. In P. Gilbert(Ed), Compassion: Conceptualization, research and use in psychotherapy (pp.239-262). London: Routledge, 2005.

[17] Gilbert, P. \& Procter, S. "Compassionate mind training for people with high shame and self-criticism: Overview and pilot study of a group therapy approach“. Clinical 
Psychology and Psycho therapy, 13, 353-379, 2006.

DOI: http://dx.doi.org/10.1002/cpp.507

[18] Neff, K. D, Hseih, Y, \& Dejitthirat, K. "Self-compassion, achievement goals, and coping with academic failure". Self and Identity, 4,263 - 287, 2005.

DOI: http://dx.doi.org/10.1080/13576500444000317

[19] Sbarra,D.A, Smith, H. L, \& Mehl, M. R. "When leaving your Ex, love yourself: Observational ratings of self-compassion predict the course of emotional recovery following marital separation". Psychological Science, 23(3), 261 - 269, 2012.

DOI: http://dx.doi.org/10.1177/0956797611429466

[20] Vettese, L. C, Dyer, C. E, Li, W. L, \& Wekerle, C. "Does self-compassion mitigate the association between childhood maltreatment and later emotional regulation difficulties?" International Journal of Mental Health and Addiction, 9, 480 - 491, 2011.

DOI: http://dx.doi.org/10.1007/s11469-011-9340-7

[21] Neff, K. D, \& Beretvas, S.N. "The role of self-compassion in romantic relationships". Self and Identity,12,78-98, 2013. DOI: http://dx.doi.org/10.1080/15298868.2011.639548

[22] Yarnell, L. M, \& Neff, K. D. "Self-compassion, interpersonal conflict resolutions, and well-being". Self and Identity,12,146-159,2013.

DOI: http://dx.doi.org/10.1080/15298868.2011.649545

[23] Neff, K. D, \& Pommier, E. "The relationship between self-compassion and other-focused concern among college undergraduates, community adults, and practicing meditators". Self and Identity, 2012.

DOI: http://dx.doi.org/10.1080/15298868.2011.649546.

[24] Lee, W. K., Cho, S. M., \& Hwang, T. Y. Korean version of Mindfulness-based cognitive Therapy for depression Seoul: Hakjisa, 2006.

[25] Park, S.H. "Development of the mindfulness scale". Doctoral dissertation. Kora: Catholic University, 2006.

[26] Kim, K.E, Yi, G.D, Cho, Y.R., Chai, S.H, \& Lee, W.K. The validation study of the Korean version of the Self-Compassion Scale“. Korean Journal of Health Psychology, 13, 1023-104, 2008.

[27] Watson, D., Clark, L.A, \& Tellegen, A. "Development and validation of brief measures of positive and negative affect: The PANAS scales". Journal of Personality and Social Psychology, 54, 1063-1070. 1988.

DOI: http://dx.doi.org/10.1037/0022-3514.54.6.1063

[28] Cho, Y. R. "Assessing emotion dysregulation : Psychometric properties of the Korean version of the Difficulties in Emotion Regulation Scale”. Korean Journal of Clinical Psychology, 26(4),1015-1038, 2007.
[29] Beck, A.T, Steer, R.A, \& Brown, G.K.(1996). Manual for Beck Depression Inventory II (BDI-II). San Antonio, TX: Psychology Corporation. 1996.

[30] Lee, Y.H., \& Song, J.Y. "A study of the reliability and the validity of the BDI , SDS , and MMPI-D Scales”. Korean Journal of Clinical Psychology, 10, 98-113, 1991.

[31] Ryff, C .D., \& Keyes, C.L.M. "The structure of psychological well-being revisited". Journal of Personality and Social Psychology,73, 549-559, 1995.

DOI: http://dx.doi.org/10.1037/0022-3514.69.4.719

[32] Kim, M.S, Kim, H.W, \& Cha, K.H. "Analyses on the construct of psychological well-being of Korean male and female adults". Korean Journal of Social and Personality Psychology, 15(2), 19-39, 2001.

[33] Williams, K., Kolar, M.M, Reger, B.E, \& Pearson, J.C. "Evaluation of a wellness-based mindfulness stress reduction intervention: A controlled trial”. American Journal of Health Promotion,15, 422-432, 2001. DOI: http://dx.doi.org/10.4278/0890-1171-15.6.422

[34] Chiesa, A, \& Serretti, "A. Mindfulness-based stress reduction for stress management in healthy people: A review and meta-analysis". The Journal of Alternative and Complementary Medicine,15(5),593 - 600, 2009.

[35] Hofmann, S. G, Sawyer, A. T, Witt, A. A, \& Oh, D. “The effect of mindfulness-based therapy on anxiety and depression: A meta-analytic review". Journal of Consulting and Clinical Psychology,78(2),169-183, 2010. DOI: http://dx.doi.org/10.1037/a0018555

[36] Birnie, K., Speca, M., \& Carlson, L. E. "Exploring Self-compassion and Empathy in the Context of Mindfulness-based Stress Reduction (MBSR)“. Stress and Health, 26, 359 - 371, 2010.

DOI: http://dx.doi.org/10.1002/smi.1305

[37] Rimes, K. A. \& Wingrove, J. Pilot study of "Mindfulness-Based Cognitive Therapy for trainee clinical psychologists". Behavioural and Cognitive Psychotherapy, 39(2), 235 - 241, 2011.

[38] Shapiro, S. L, Brown, K.W, \& Biegel,G.M. “Teaching self-care to caregivers: Effects of mindfulness based stress reduction on the mental health of therapists in training”. Training and Education in Professional Psychology,1,105 - 115, 2007.

DOI: http://dx.doi.org/10.1037/1931-3918.1.2.105

[39] K. W. Brown and R. M. Ryan, "The benefits of being present: mindfulness and its role in psychological well-being“, Journal of Personality and Social Psychology, vol. 84, no. 4,pp. 822 - 848, 2003.

DOI: http://dx.doi.org/10.1037/0022-3514.84.4.822 
Woo-Kyeong Lee

[Regular member]

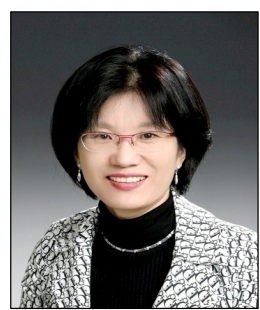

- Feb. 1989 : Hankuk Univ. of Foreign Studies

- Feb. 1998 : Catholic University Department of Psychology Master degree

- Aug. 2008 : Ewha University Department of Psychology PhD

- Sep. 2010년 current : Department of Counseling Psychology Seoul Cyber Univ. Professor

$<$ Research Interests $>$

Cognitive therapy, Addiction, Mindfulness meditation

\section{Se-Jin Ju}

[Regular member]

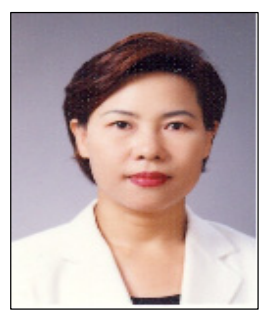

- Feb. 1985 : Seoul National Univ. Public Health MS

- Feb. 2005 : Seoul National Univ Ph.D.

- Mar. 1993 Feb. 2010 : Seoul National Univ Hospital Psychiatric Nurse Specialist

- Mar. 2010 current : Namseoul Univ. Professor. Nursing Department

$<$ Research Interests $>$

Autism, Suicide, Addiction, Mindfulness meditation 